\title{
Exploring the Benefits of Annular Rectangular Rib for Enhancing Thermal Efficiency of Nonpremixed Micro-Combustor
}

\author{
Hongcai Wang, ${ }^{1}$ Hongru Fang, ${ }^{1}$ Bingqian Lou, ${ }^{1}$ Shitu Abubakar $\mathbb{D}^{2},{ }^{2}$ Yuqiang Li $\mathbb{D},{ }^{1}$ \\ and Lei Meng ${ }^{3}{ }^{3}$ \\ ${ }^{1}$ School of Energy Science and Engineering, Central South University, Changsha 410083, China \\ ${ }^{2}$ College of Mechanical and Electrical Engineering, Central South University, Changsha 410083, China \\ ${ }^{3}$ School of Automation, Wuhan University of Technology, Wuhan 430070, China
}

Correspondence should be addressed to Yuqiang Li; csulyq@csu.edu.cn and Lei Meng; menglei1986@gmail.com

Received 5 October 2019; Revised 8 December 2019; Accepted 20 January 2020; Published 13 February 2020

Guest Editor: Yaojie Tu

Copyright (c) 2020 Hongcai Wang et al. This is an open access article distributed under the Creative Commons Attribution License, which permits unrestricted use, distribution, and reproduction in any medium, provided the original work is properly cited.

Micro-combustor can provide the required thermal energy of micro-thermal photovoltaic (MTPV) systems. The performance of MTPV is greatly affected by the effectiveness of a micro-combustor. In this study, a numerical simulation was conducted to explore the benefits of annular rectangular rib for enhancing the thermal performance of a nonpremixed micro-combustor. Based on the investigations under various rib heights, rib positions, and inlet mass flow rates, it is found that the addition of annular rectangular ribs in the micro-combustor creates a turbulent zone in the combustion chamber, thereby enhancing the heat transfer efficiency between the inner wall of the combustion chamber and the burned gas. The micro-combustor with annular rectangular rib shows a higher and more uniform wall temperature. When the $\mathrm{H}_{2}$ mass flow is $7.438 \times 10^{-8} \mathrm{~kg} / \mathrm{s}$ and the air mass flow is $2.576 \times 10^{-6} \mathrm{~kg} / \mathrm{s}$, the optimum dimensionless rib position is at $l=6 / 9$ and $r=0.4$. At this condition, the micro-combustor has the most effective and uniform heat transfer performance and shows significant decreases in entropy generation and exergy destruction. However, the optimum $l$ and $r$ significantly depend on the inlet mass flow of $\mathrm{H}_{2} /$ air mixture.

\section{Introduction}

The micro-power system has the characteristics of small capacity, high heat loss, unstable combustion, etc. and is more unstable than macroscopic combustion. Some prototypes of micro-power devices have been extensively developed and studied, like micro-combustion batteries, micro-turbines, and micro-thermal photovoltaic (MTPV) systems. In recent years, micro-thermal photovoltaic (MTPV) systems have been receiving much attention due to their potential application as reliable energy sources. In MTPV system, the heat energy is generated after the combustion of fuel, the radiation wall of micro burner can convert the heat energy into radiation photons with a certain amount of energy through its radiation characteristics, and some of the radiation photons are received by the evenly distributed photocell elements on the wall of micro burner and then converted into electrical energy and output to the outside. Conventionally, micro-combustor often uses hydrogen and hydrocarbon compounds as fuel and has some advantages such as high energy conversion efficiency, simple physical structure, and substantial energy output per unit volume. To enhance the energy conversion efficiency of micro-combustor, a lot of methods have been investigated and reported in the literature. The micro-combustor is designed to achieve improved heat transfer performance, and the improved combustor presents higher and more uniform wall temperature, which is the yardstick for its performance appraisal.

Numerous scholars have established novel micro-combustion chambers by adopting various methods for realizing high and uniform wall temperature. Chou et al. [1] have successfully used porous media. Pan et al. [2] and Li et al. [3-5] improved flame stability in the microchannel by enhancing heat transfer. Catalytic combustion can be used to improve fuel conversion efficiency [6-11]. The Swiss roll 
combustor's combustion characteristics have been extensively studied by Vijayan and Gupta $[12,13]$, Shirsat and Gupta [14], and Wierzbicki et al. [15]. It can be seen from the results that Swiss roll combustor extremely improves the combustion stability and also extends the extinction limit. Bagheri and Hosseini [16] investigated two different thermal cycling combustors and compared their heat loss, flame propagation, flame thickness, excess enthalpy, velocity, and emitter efficiency. Hosseini and Wahid [17] investigated the characteristics of two difference flameless states of $\mathrm{CH}_{4} /$ air. Their findings show that micro-flameless combustion is smoother with using bluff-body. Wan et al. $[18,19]$ proposed a micro cavity-combustor. It can be concluded from their findings that, with the increase of equivalent ratio, the flame limit is extended. Another method which is also considered effective is heat recirculating $[20,21]$. The irreversible energy loss caused by combustion of the fuel cannot be neglected. Jejurkar and Mishra [22] carried out related research about the relationship between micro-combustor performance and thermal conductivity of the wall, and the findings of the study show that, at higher thermal conductivities, the wall heat losses unfavorably influenced the exergetic property of micro-combustor. Moreover, the thermal conductivity of the wall in the range of $0.1-1.75 \mathrm{~W} / \mathrm{m} \cdot \mathrm{K}$ was discovered to be appropriate for obtaining high exergetic efficiency and uniform wall temperature. Briones et al. [23] examined the propagation of a layered $\mathrm{H}_{2}$-rich $\mathrm{CH}_{4}$ air flame by numerical method. The results show that as the $\mathrm{H}_{2}$ content in the fuel increases, both heat transfer and chemical reactivity increase, leading to an increase in entropy.

Moreover, MTPV system also has the problem of low total energy conversion efficiency [24-27]. Research has indicated that the uniformity of combustion chamber wall temperature influences the energy conversion efficiency of MTPV system [28]. In addition, [4, 23] Li et al. [4, 29, 30] established that the use of porous media contributed immensely to the wall temperature rise, which translates into the efficiency of the combustor. Yang et al. conducted experiments by adding heat recuperator [30] or a block [31] insert in micro-combustors. The results show that both methods can effectively improve the uniformity of wall temperature distribution. Jiang et al. [32,33] researched the effect of block inserts (baffles) on combustor efficiency. The effective position of the baffles was ascertained, which significantly improved the uniformity of the wall temperature distribution. Tang [34] and Su et al. [35] established a multichannel micro-combustors for micro-thermal photovoltaic systems. Under various conditions, the premixed $\mathrm{H}_{2} /$ air mixture combustion behavior was researched. The results show that the outer wall temperature of the multichannel micro-combustor is significantly enhanced compared to the single-channel micro-combustor. Chen et al. [36-38] used the lattice Boltzmann model to solve the governing equations of the premixed and nonpremixed reverse jet $\mathrm{H}_{2}$-air combustion process and found different entropy generation analysis features from previous studies. Moreover, Emadi and Emami [39] investigated the exergy loss and the local entropy generation of $\mathrm{CH}_{4}$-air bluff-body flame burning in the combustor under turbulent nonpremixed $\mathrm{H}_{2}$-enriched.
It was shown that exergy loss and entropy generation are reduced by adding $\mathrm{H}_{2}$. Datta [40] investigated diffusion flames in constrained geometries at different gravity levels to analyze the effect of gravity on the second law efficiency and entropy production rate. The results showed that, under normal gravity, the entropy production rate caused by heat transfer was significantly increased compared to zero gravity and, at all gravity levels, the entropy production rate caused by chemical reactions and mass transfer was almost constant.

These experimental studies reveal the importance of flame stability and thermal characteristics to the combustor performance and introduce several effective combustion chamber structural designs and methods. Ban et al. [41] studied the effect of buoyancy on different flames by examining the flame shape for horizontally oriented combustors. However, they did not study the effect of extended surfaces for better heat transfer. Resende et al. [42] summarized the pertinent investigations revolved around nonpremixed diffusion combustion regime, which is commonly employed in practical systems. The review has pinpointed important factors for realizing improved burner performance such as the burner configuration. Research is still relevant to nonpremixed $\mathrm{H}_{2}$ /air combustion by considering some influential geometric parameters that promote the efficiency of the combustion process. This study is aimed at finding a suitable combustion structure that provides elevated outer wall temperature and exhibits effective and uniform heat transfer distribution for the nonpremixed micro-combustor. A nonpremixed micro-combustor with annular rectangular rib was proposed, and the effect of annular rectangular ribs on the heat transfer performance of the nonpremixed micro-combustor was numerically investigated under varying air and $\mathrm{H}_{2}$ mass flow rate, rib position, and rib height.

\section{Numerical Model}

2.1. Physical Model of Micro-Combustor. Figure 1 shows the schematic of a micro-combustor combining a backward step and a cavity [43]. The micro-combustor has an overall maximum outer diameter of $1.6 \mathrm{~mm}$ and a length of $12 \mathrm{~mm}$. The front end and the rear end of the micro-combustor have dissimilar internal contours. The front end is contoured into four tubes: the suction pipe A, the mixing pipe B, the diffusion pipe $C$, and the shrink pipe D. Hydrogen and air simultaneously enter into the micro burner through the inlet side; the hydrogen inlet is a circular shape with a diameter of $0.2 \mathrm{~mm}$, and the air inlet is an annular passage with the outer diameter of $0.862 \mathrm{~mm}$ and the inner diameter of $0.6 \mathrm{~mm}$.

Hydrogen and air enter the micro-combustor through the central circular passage and the outer annular passage of the suction pipe A, respectively. The shrinking shape of the straw A enables the air and hydrogen to obtain oblique velocities toward the centerline. In the mixing pipe $B$, air and $\mathrm{H}_{2}$ are mixing. Furthermore, the arrangement of the diffuser tube $\mathrm{C}$ enables the dynamic pressure portion to be converted into static pressure, thereby increasing the pressure difference, while the suction efficiency is also enhanced by the 


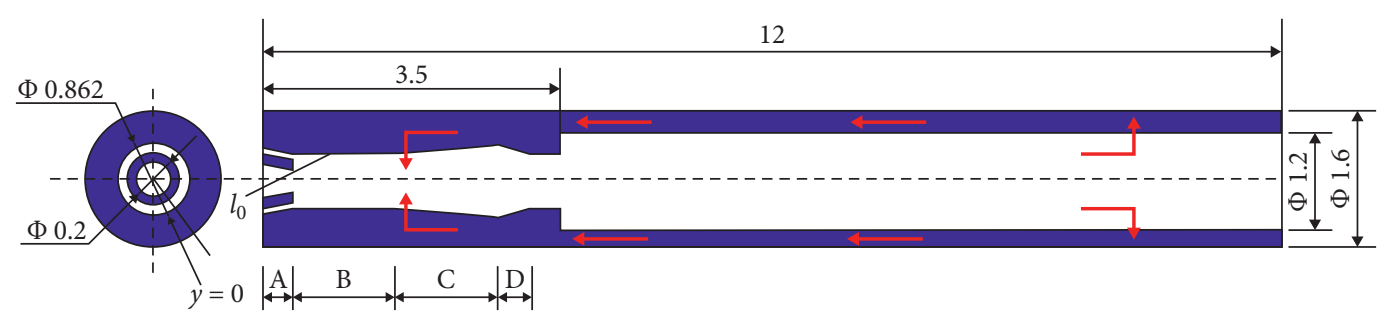

FIgURE 1: Schematic of the micro-combustor (units in $\mathrm{mm}$ ).

action of the diffuser pipe C. The shrinkage pipe $D$ is provided to prevent tampering [44].

As shown in Figure 2, the model shown in Figure 1 is modified by adding an annular rectangular rib at a certain distance from combustor inlet, and the channel is divided into two parts. The fixed width of the annular rectangular rib is $1.0 \mathrm{~mm}$, and the position $(L 3)$ and height $(H)$ of the annular rectangular rib are variable geometric parameters. By setting the height and position of the dimensionless annular rectangular ribs to $r=2 H / d 3$ and $l=L 3 / L 1$, respectively, the effect of the annular rectangular ribs on the outer wall temperature of the micro-combustor can be investigated.

In nonpremixed micro-combustor, to better study the influence of ribs on the combustion characteristics, as shown in Table 1, the optimum rib positions and rib heights that are suitable for higher efficiency of a micro-combustor were determined. The model parameters of four different rib heights and different rib positions are set in this study to conduct a thorough parameter comparison study. The combustors shown in Figures 1 and 2 are both made of steel material with good thermal conductivity and good corrosion resistance.

2.2. Mathematical Model. In combustion simulation of micro-combustor, assuming hydrogen with light weight, small volume, long life, and high-efficiency density, in the reactants, gaseous substances can be considered as a continuous medium, expressed by the Navier-Stokes equation. Owing to the mass flow of $\mathrm{H}_{2}$ and the low rate of air, the effects of dissipative forces and fluid volume are ignored. The modeling considers various equations. These equations are defined as follows:

Conservation equation of mass:

$$
\frac{\partial}{\partial x}(\rho u)+\frac{1}{r} \frac{\partial}{\partial r}(\rho v r)=0 .
$$

Momentum conservation equation:

$$
\frac{\partial}{\partial x_{j}}\left(\rho u_{i} u_{j}-\tau_{i j}\right)=-\frac{\partial p}{\partial x_{i j}} .
$$

Energy conservation equation:

$$
\frac{\partial}{\partial x_{j}}\left(\rho u_{j} h+F_{i, j}\right)=u_{j} \frac{\partial p}{\partial x_{j}}+\tau_{i j} \frac{\partial u_{i}}{\partial x_{j}} .
$$

Species equation:

$$
\frac{\partial}{\partial x_{j}}\left(\rho u_{j} m_{l}+J_{l, j}\right)=R_{l} .
$$

Wall energy conservation equation:

$$
\frac{\partial\left(\lambda_{w} \partial T\right)}{\partial x_{i}^{2}}=0 .
$$

Ideal gas equation:

$$
P=\rho R T \sum \frac{m_{l}}{M_{1}}
$$

For the sake of acquiring the optimum annular rectangular ribs settings to enhance the temperature and its uniformity of the outer wall, the positions of the ribs and the rib heights geometry were varied and studied using numerical simulation. In the analysis, the outer wall temperature difference is adopted in expressing the uniformity of heat transfer of the micro-combustor, and its outer wall temperature difference can be expressed as follows:

$$
\nabla T=T_{\text {outwall,max }}-T_{\text {outwall,min }} .
$$

Entropy transport equation:

$$
T d s=d u+p d\left(\frac{1}{\rho}\right)-\sum_{j=1}^{n} d\left(\frac{n_{j}}{\rho}\right) .
$$

Consequently, the total entropy generation $S_{\text {gen }}$ is written as follows:

$$
S_{\text {gen }}=m s
$$

In a combustion process, because the exergy destruction $E_{\text {des }}$ and the total entropy generation are in the direct ratio, it is expressed as follows:

$$
E_{\text {des }}=S_{\text {gen }} T_{0} .
$$

2.3. Computational Mesh and Boundary. Due to the complexity of the geometric model, which consisted of a backward-facing step and four pipes, numerical simulation of 2D models using CFD Fluent 19.0 was carried out. Some researches [43, 45, 46] have suggested that the turbulent model can accurately predict combustion behaviors at the inlet flow $\operatorname{Re}>500$. As a result, standard $k-\varepsilon$ model is chosen in this work. The combustion reaction only involves the combustion of hydrogen; the chemical kinetic mechanism of Fluent was adopted. This mechanism comprises 11 


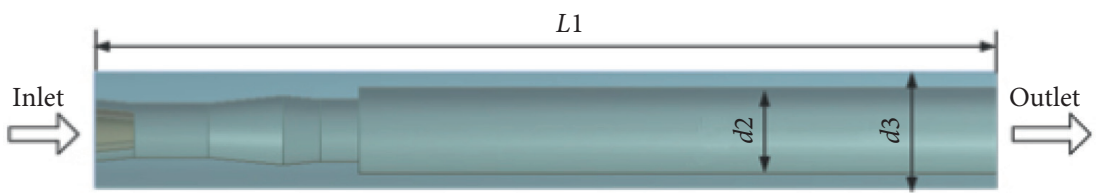

(a)

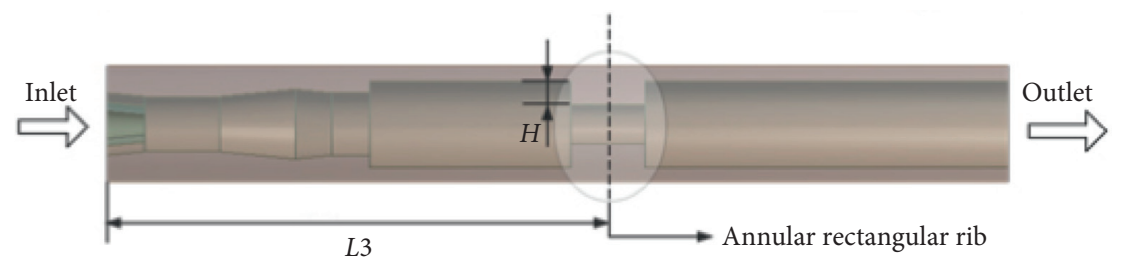

(b)

FIGURE 2: Schematic diagram of nonpremixed micro column burners: (a) without annular rectangular ribs and (b) with annular rectangular ribs.

TABLE 1: Dimensionless rib height and rib position.

\begin{tabular}{lccc}
\hline Rib height & \multicolumn{3}{c}{ Rib position } \\
\hline $4 / 9$ & 0.25 & 0.325 & 0.4 \\
$5 / 9$ & 0.25 & 0.325 & 0.4 \\
$6 / 9$ & 0.25 & 0.325 & 0.4 \\
$7 / 9$ & 0.25 & 0.325 & 0.4 \\
\hline
\end{tabular}

elementary species, and the detailed chemical reaction mechanism is shown in Table 2.

In the research, the simulated combustion of microcombustor uses standard $k-\varepsilon$ model. The $\mathrm{H}_{2}$ and air mass flow rates are both considered as the inlet boundary conditions, while the outlet pressure was used as the outlet boundary condition. The ambient temperature is $298 \mathrm{~K}$ and the ambient pressure is $1.01 \times 10^{5} \mathrm{~Pa}$. At the same time, the no-slip boundary condition is adopted. Both convective and radiative heat transfer of the environment are considered in the outer wall of the combustion chamber. For the convergence criterion, it is also necessary to set the residual value; the residuals for velocity and continuity are set as $1 \times 10^{-3}$, and the residuals for do-intensity and energy are set as $1 \times 10^{-6}$. The equations involved are all set to secondorder upwind scheme discretization.

This study presents the nonpremixed micro column combustor, with an annular rectangular shape rib. Therefore, in order to expedite the calculation process, the analysis was simplified to a two-dimensional numerical analysis at the center of a section.

Table 3 provides the model boundary condition; massflow-rate boundary condition was adopted for inlet, and the pressure-outlet boundary was employed for the outlet. In both boundaries the gauge pressure is set to $0 \mathrm{MPa}$.

A unified $2 \mathrm{D}$ grid is built to calculate the heat transfer and the combustion in the micro-combustor. A model grid of micro-combustor is generated as presented in Figure 3. For the case where the value of equivalence ratio is 1.0 , the air and $\mathrm{H}_{2}$ mass flow rates are maintained at $4.632 \times 10^{-6}$ and $1.347 \times 10^{-7} \mathrm{~kg} / \mathrm{s}$, respectively. Grid-independent testing was performed by modifying the number of elements to a finer
TABle 2: Chemical reaction mechanism of H/air combustion.

\begin{tabular}{lccc}
\hline Reactions & $\begin{array}{c}A_{k} \\
\left(\mathrm{~m}^{3} /(\mathrm{kmol} \mathrm{s})\right)\end{array}$ & $\beta_{k}$ & $E_{k}(\mathrm{~J} / \mathrm{kmol})$ \\
\hline 1. $\mathrm{O}_{2}+\mathrm{H}=\mathrm{O}+\mathrm{OH}$ & $3.55 \times 10^{12}$ & -0.4 & $6.945 \times 10^{7}$ \\
2. $\mathrm{O}+\mathrm{H}_{2}=\mathrm{H}+\mathrm{OH}$ & 50.8 & 2.7 & $2.632 \times 10^{7}$ \\
3. $\mathrm{H}_{2}+\mathrm{OH}=\mathrm{H}_{2} \mathrm{O}+\mathrm{H}$ & $2.16 \times 10^{5}$ & 1.5 & $1.435 \times 10^{7}$ \\
4. $\mathrm{O}+\mathrm{H}_{2} \mathrm{O}=2 \mathrm{OH}$ & 2970 & 2 & $5.607 \times 10^{7}$ \\
5. $\mathrm{H}_{2}=2 \mathrm{H}$ & $4.58 \times 10^{16}$ & -1.4 & $4.351 \times 10^{8}$ \\
6. $2 \mathrm{O}=\mathrm{O}_{2}$ & $6.16 \times 10^{9}$ & -0.5 & 0 \\
7. $\mathrm{O}+\mathrm{H}=\mathrm{OH}$ & $4.71 \times 10^{12}$ & -1 & 0 \\
8. $\mathrm{H}+\mathrm{OH}=\mathrm{H}_{2} \mathrm{O}$ & $3.8 \times 10^{16}$ & -2 & 0 \\
9. $\mathrm{H}+\mathrm{O}_{2}=\mathrm{HO} \mathrm{O}_{2}$ & $1.48 \times 10^{9}$ & 0.6 & 0 \\
10. $\mathrm{HO}_{2}+\mathrm{H}=\mathrm{H}_{2}+\mathrm{O}_{2}$ & $1.66 \times 10^{10}$ & 0 & $3.443 \times 10^{6}$ \\
11. $\mathrm{HO}_{2}+\mathrm{H}=2 \mathrm{OH}$ & $7.08 \times 10^{10}$ & 0 & $1.234 \times 10^{6}$ \\
12. $\mathrm{HO}_{2}+\mathrm{O}=\mathrm{O}_{2}+\mathrm{OH}$ & $3.25 \times 10^{10}$ & 0 & 0 \\
13. $\mathrm{HO}_{2}+\mathrm{OH}=\mathrm{H}_{2} \mathrm{O}+\mathrm{O}_{2}$ & $2.89 \times 10^{10}$ & 0 & $-2.08 \times 10^{6}$ \\
14. $2 \mathrm{HO}_{2}=\mathrm{H}_{2} \mathrm{O}_{2}+\mathrm{O}_{2}$ & $4.2 \times 10^{11}$ & 0 & $5.021 \times 10^{7}$ \\
15. $\mathrm{H}_{2} \mathrm{O}_{2}=2 \mathrm{OH}$ & $2.95 \times 10^{14}$ & 0 & $2.025 \times 10^{8}$ \\
16. $\mathrm{H}_{2} \mathrm{O}_{2}+\mathrm{H}=\mathrm{H}_{2} \mathrm{O}+\mathrm{OH}$ & $2.41 \times 10^{10}$ & 0 & $1.661 \times 10^{7}$ \\
17. $\mathrm{H}_{2} \mathrm{O}_{2}+\mathrm{H}=\mathrm{HO}_{2}+\mathrm{H}_{2}$ & $4.82 \times 10^{10}$ & 0 & $3.326 \times 10^{7}$ \\
18. $\mathrm{H}_{2} \mathrm{O}_{2}+\mathrm{O}=\mathrm{OH}_{+}+\mathrm{HO}_{2}$ & 9550 & 2 & $1.661 \times 10^{7}$ \\
19. $\mathrm{H}_{2} \mathrm{O}_{2}+\mathrm{OH}=\mathrm{HO}_{2}+\mathrm{H}_{2} \mathrm{O}$ & $1 \times 10^{9}$ & 0 & 0 \\
\hline
\end{tabular}

Note: $A_{k}$ is the preexponential factor of reaction rate, $\beta_{k}$ is the temperature exponent, and $E_{k}$ is the activation energy of the reaction.

Table 3: Model boundary condition.

\begin{tabular}{lcc}
\hline \multirow{3}{*}{$\mathrm{H}_{2}$ inlet } & $\mathrm{H}_{2}$ mass flow (kg/s) & $7.483 \times 10^{-8}$ \\
& Turbulence intensity & $5 \%$ \\
\multirow{4}{*}{ Air inlet } & Hydraulic diameter & 0.0004 \\
& Air mass flow (kg/s) & $2.573 \times 10^{-6}$ \\
Pressure outlet & Turbulence intensity & $5 \%$ \\
\multirow{2}{*}{ Outer wall } & Hydraulic diameter & 0.001 \\
& Turbulence intensity & $5 \%$ \\
& Hydraulic diameter $(\mathrm{m})$ & 0.0012 \\
& Heat transfer coefficient & 10 \\
& Emissivity & 0.85 \\
\hline
\end{tabular}

one and is presented in Figure 4. By observing and comparing three different grids, the three grids have 15719, 19061, and 23987 cells, respectively. The mesh with 15719 


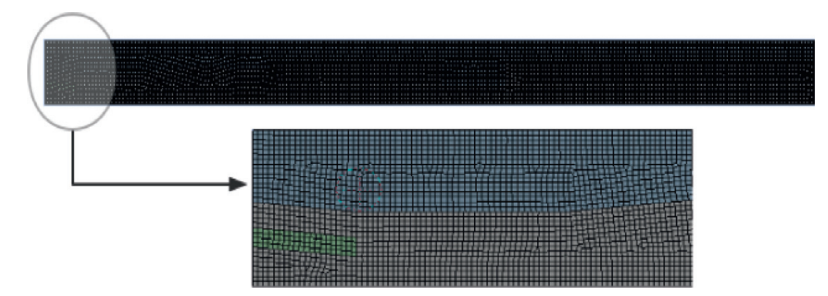

Figure 3: Computational mesh of nonpremixed micro-combustor.

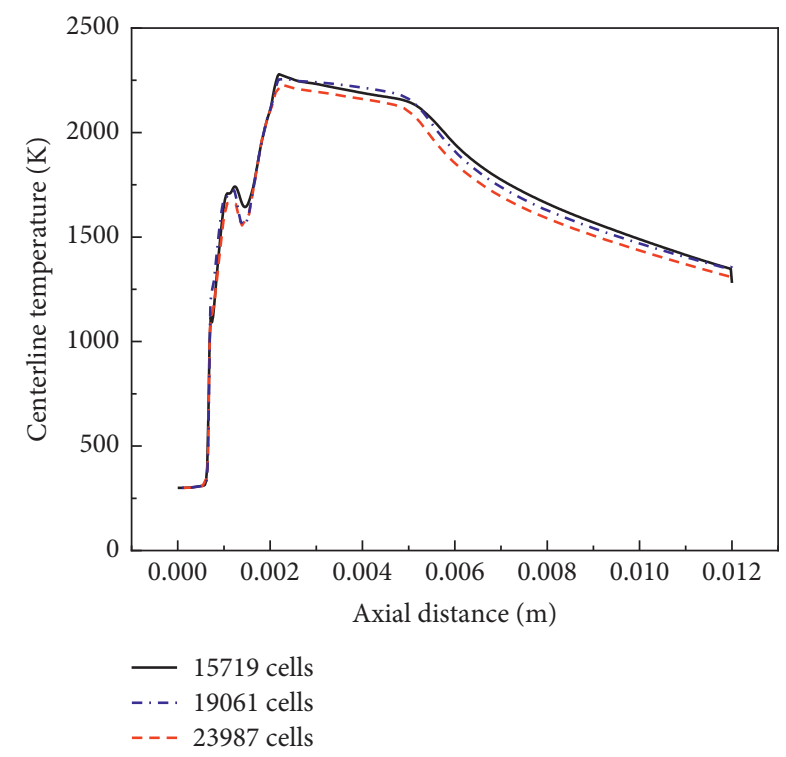

Figure 4: Axial temperature profile of simulation.

cells and the mesh with 23987 cells are of the highest and lowest temperature on centerline, respectively. Moreover, temperature difference of the resulting centerline temperature profile is diminutive under three different numbers of grids. Therefore, the mesh with 19061 cells has better accuracy and less computation time, making it more suitable for numerical investigation.

2.4. Model Validation. The simulated results were compared with the experimental results to confirm the validation of the model. And the experimental results are obtained from the group of E. In the experiments in a silicon material microcombustor, the $\mathrm{H}_{2}$ and the air mass flow are maintained at $1.347 \times 10^{-7} \mathrm{~kg} / \mathrm{s}$ and $4.632 \times 10^{-6} \mathrm{~kg} / \mathrm{s}$, respectively. The measurement points of the experiment are situated at 2, 5, 8, and $10 \mathrm{~mm}$ in the axial length of the micro-combustor.

Experimental outer wall temperature at varying combustor lengths [43] and the numerical prediction are compared as represented in Figure 5. The temperature data of the corresponding position is calculated by simulating the hydrogen inlet mass flow of $1.347 \times 10^{-7} \mathrm{~kg} / \mathrm{s}$ and the equivalence ratio of 1.0. In order to obtain a viable model, the deviation of the experimental results and the numerical results should be as small as possible. As can be seen from Figure 5, the deviation is less than $4.72 \%$. Therefore, it is feasible to analyze the performance of the micro-combustor by simulation.

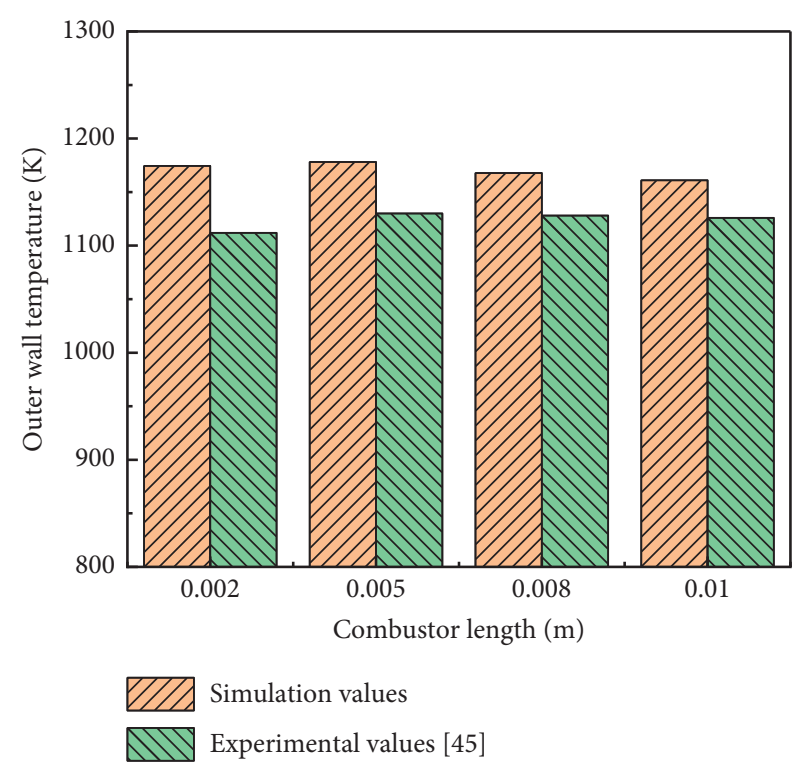

FIGURE 5: Comparison between simulated and experimental values.

\section{Results and Discussions}

3.1. Effects of Annular Rectangular Rib on Outer Wall Temperature. Figure 6 shows the temperature cloud diagram of different $r$ and $l$. From the figure, it can be observed that the change in rib positions and rib heights of the annular rectangular ribs in the micro-combustor is proportional to the temperature distribution of flow field. Figure 7 presents the temperature distribution of the outer wall that the microcombustor has under different $l$ and $r$. The inlet $\mathrm{H}_{2}$ and the air rates of mass flow were maintained at $7.383 \times 10^{-8} \mathrm{~kg} / \mathrm{s}$ and $2.573 \times 10^{-6} \mathrm{~kg} / \mathrm{s}$ with an $\mathrm{H}_{2} /$ air equivalent ratio of 1.0 . It can be seen from the figure that when the $l$ of the microcombustor is a fixed constant, the temperature at outer wall increases as the $r$ increases. This can be explained by the fact that, by the raise of the dimensionless rib heights, the turbulence zone becomes wider, and the turbulence area at the rear of the annular rectangular rib expands in proportion to the dimensionless rib heights, effectively improving the heat transmission capability of the micro-combustor. However, it is worth noting in Figure 8 that the optimum settings for the maximum outer wall temperature are at $l=5$ / 9 and $r=0.325$. The good performance obtained is a result of the ribs being very close to the center of the flame, reducing the positive impact of expanding the turbulence area and weakening the negative influence of the annular rectangular ribs on the heat transmission of the micro-combustor.

It can be seen from Figure 8(a) that the $l$ of microcombustor is a fixed constant, and the mean outer wall temperature increases proportionally with the $r$. The changing trend of Figure 8(a) is the same as the change of the temperature distribution of outer wall in Figure 7 . Figure 8 (b) shows the temperature difference of the outer wall temperature at different rib positions and heights. The uniformity of the heat transfer of the combustor is manifested by the magnitude of the outer wall temperature difference. The smaller the difference of temperature, the 


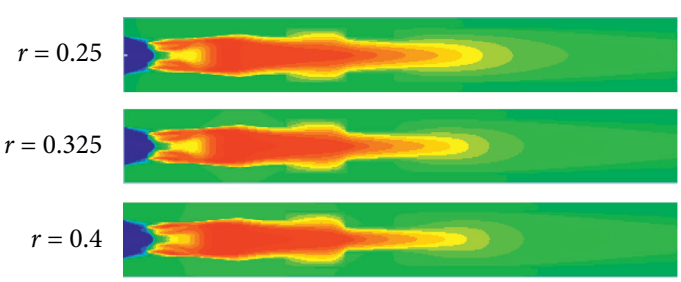

(a) $l=4 / 9$

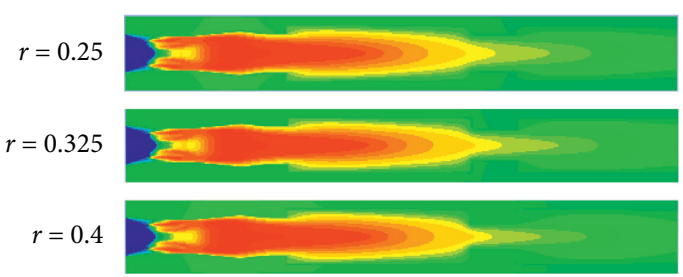

(c) $l=6 / 9$

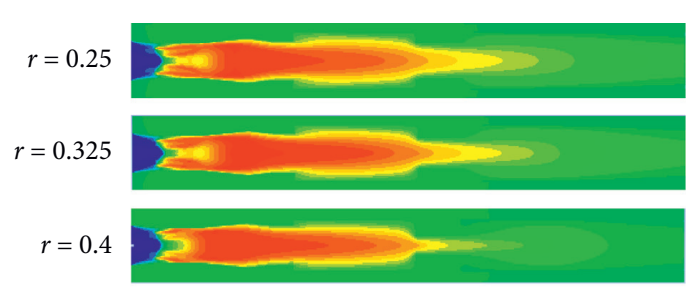

(b) $l=5 / 9$

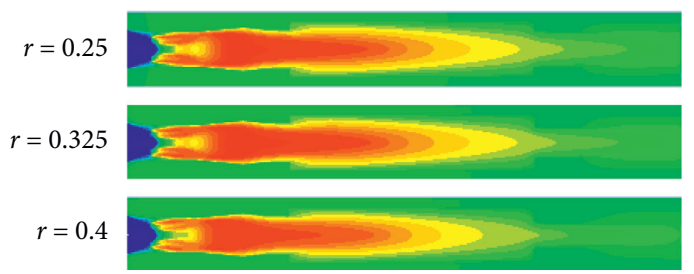

(d) $l=7 / 9$

FIgURE 6: Spatial distribution of temperature at $l=4 / 9$.

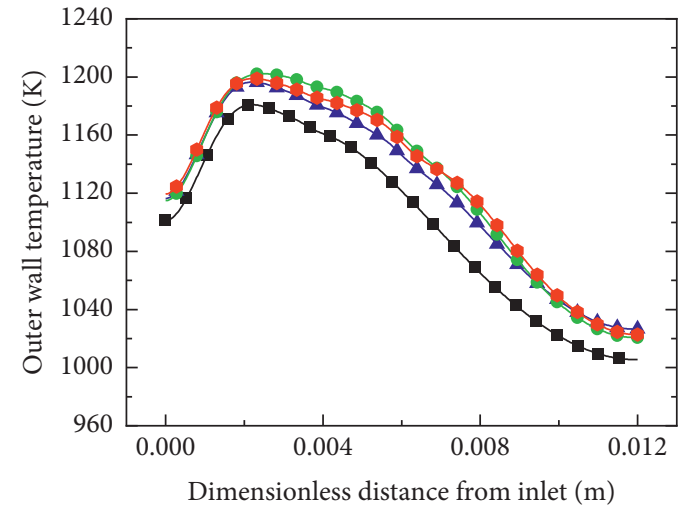

$\neg l=4 / 9, r=0.25 \quad \longrightarrow l=4 / 9, r=0.4$

$\longrightarrow l=4 / 9, r=0.325 \rightarrow$ Without rib

(a)

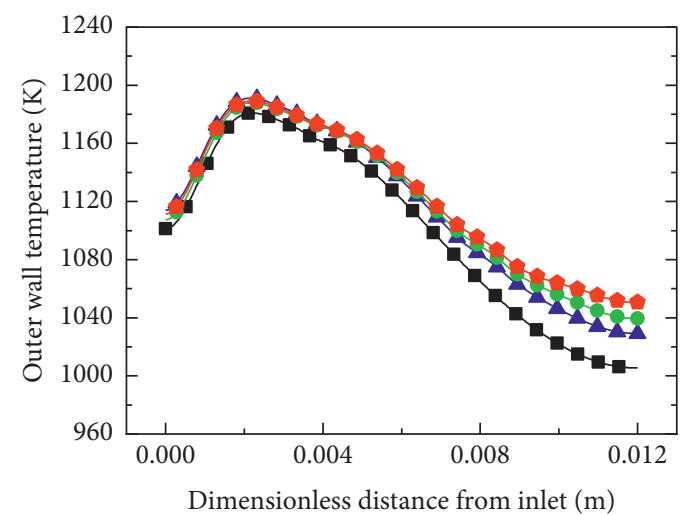

$\neg l=6 / 9, r=0.25 \quad \longrightarrow l=6 / 9, r=0.4$

(c)

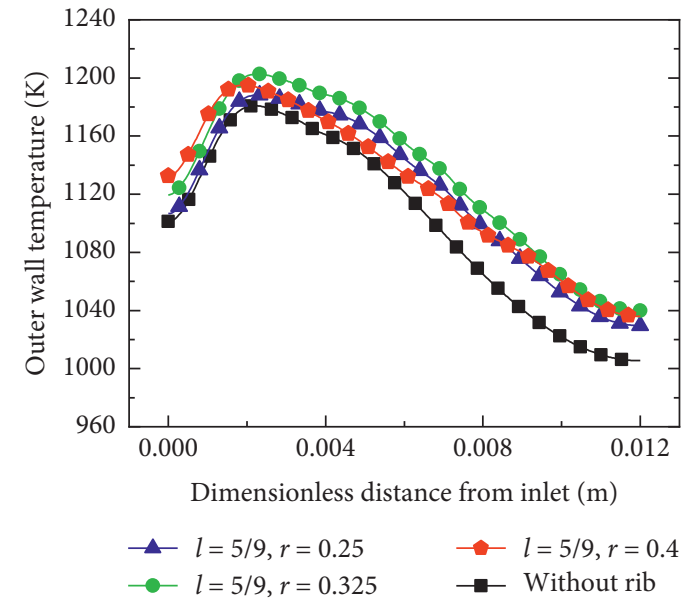

(b)

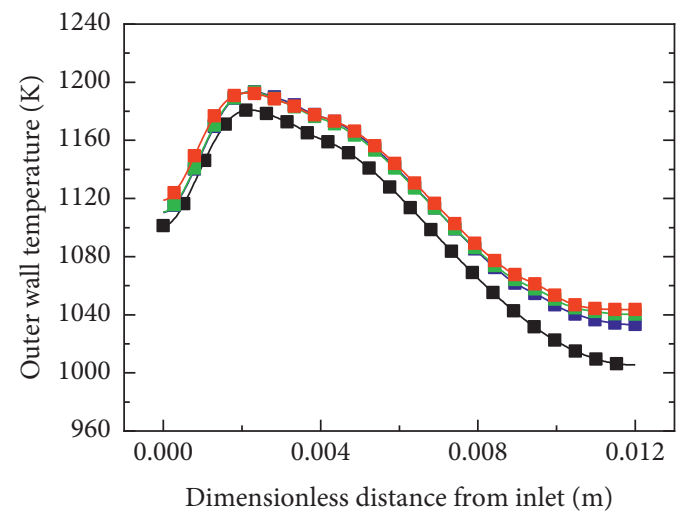

$\begin{array}{ll}\longrightarrow l=7 / 9, r=0.25 & \longrightarrow l=7 / 9, r=0.4 \\ -l=7 / 9, r=0.325 & \longrightarrow \text { Without rib }\end{array}$

(d)

Figure 7: Outer wall temperature at different rib positions and heights. 


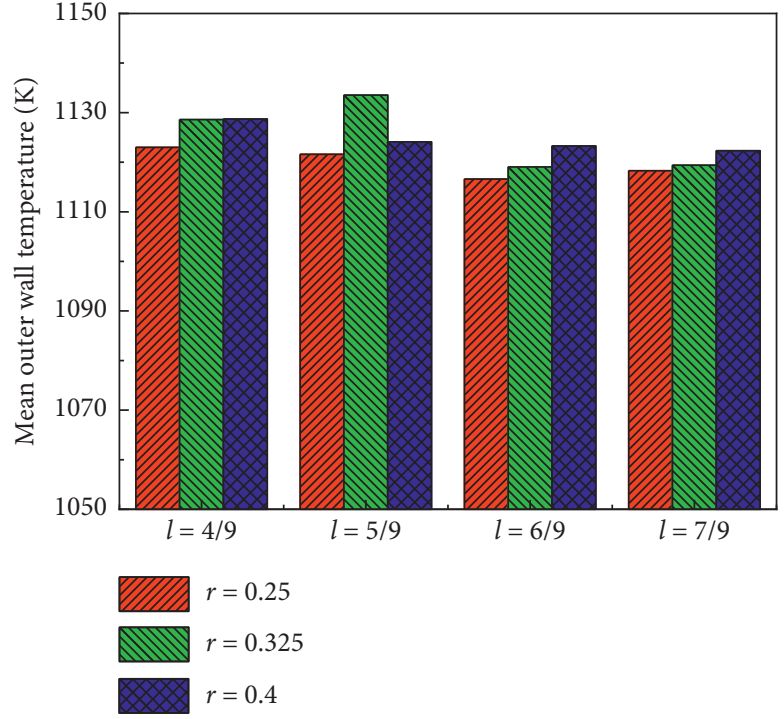

(a)

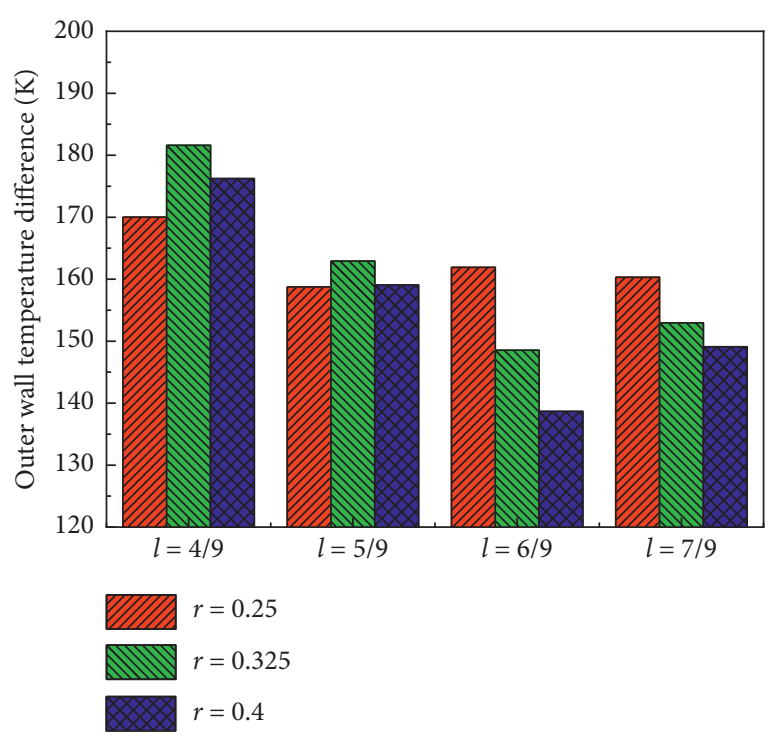

(b)

FIgURE 8: Mean outer wall temperature and outer wall temperature at various $l$ and $r$.

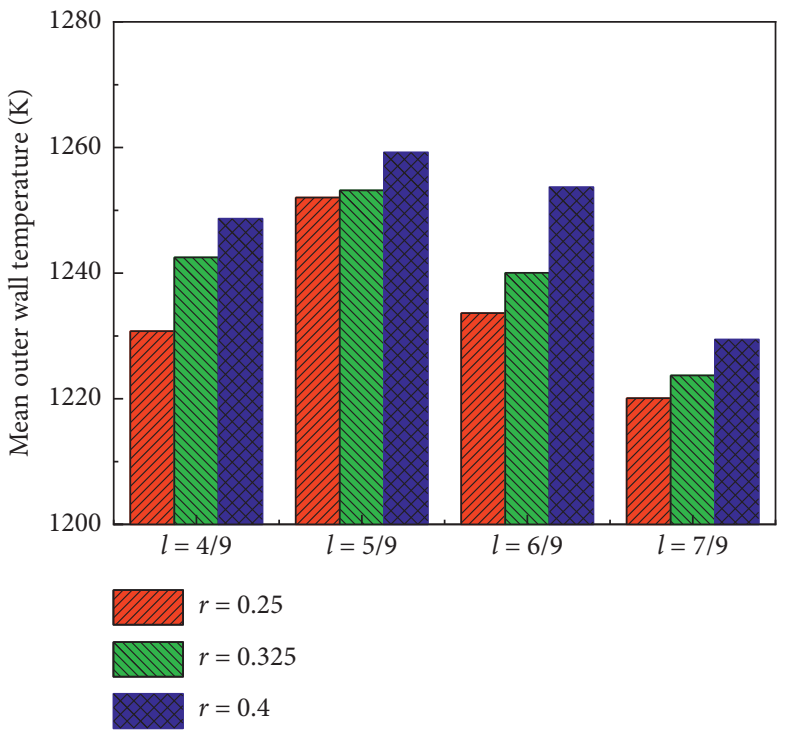

(a)

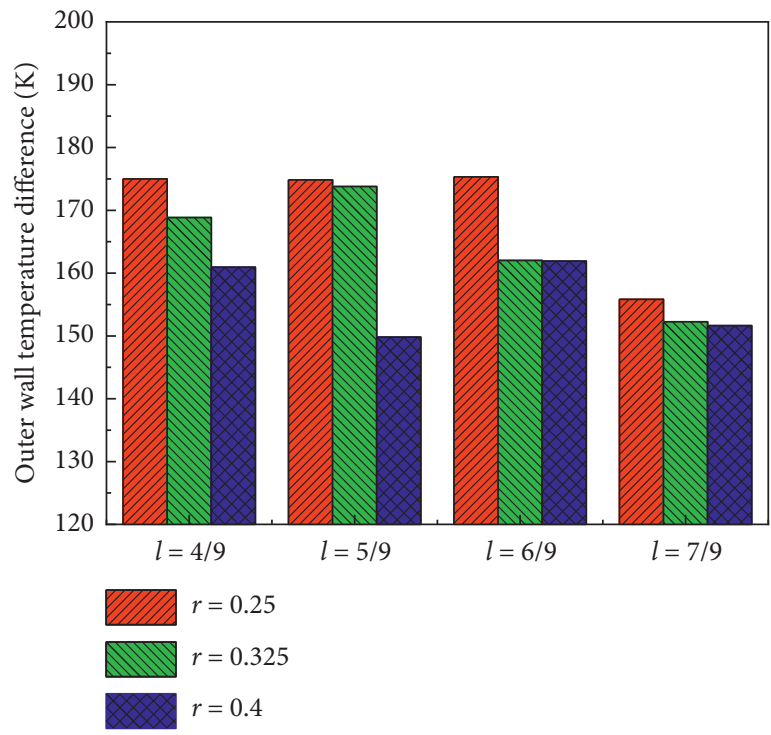

(b)

FiguRE 9: Mean outer wall temperature and outer wall temperature at different $l$ and $r$.

more uniform the heat transfer. Also, the temperature difference is maximum at $l=5 / 9$ and $r=0.325$; the temperature difference is minimum at $l=6 / 9$ and $r=0.4$, and more effective uniform heat transfer is realized.

By varying the inlet mass flow rate and repeating the above simulation experiment procedure, the results shown in Figures 9 and 10 were obtained. The inlet $\mathrm{H}_{2}$ and the air mass flow rate were maintained at $1.347 \times 10^{-7} \mathrm{~kg} / \mathrm{s}$ and $4.632 \times 10^{-6} \mathrm{~kg} / \mathrm{s}$, respectively, leading to the results obtained in Figure 9. Similarly, the inlet $\mathrm{H}_{2}$ and the air mass flow rates were maintained at $1.646 \times 10^{-7} \mathrm{~kg} / \mathrm{s}$ and $5.661 \times 10^{-6} \mathrm{~kg} / \mathrm{s}$, respectively, producing the results obtained in Figure 10. Both results were obtained at equivalence ratio of 1.0. It was observed that the position and height of the ribs with the minimum and maximum outer wall temperature are affected. This is because the increase in inlet mass flow speeds up the mass flow rate of the inlet, causing the center of the flame to move toward the rear of the micro-combustor. It can be seen from the result that the positions and heights of the rib with the best heat transfer efficiency are influenced by inlet mass flow rate and vary as the inlet flow rate changes.

3.2. Effects of Annular Rectangular Rib on Field Entropy Destruction. Exergy destruction is energy that cannot be converted into useful work in a reversible process. To further 


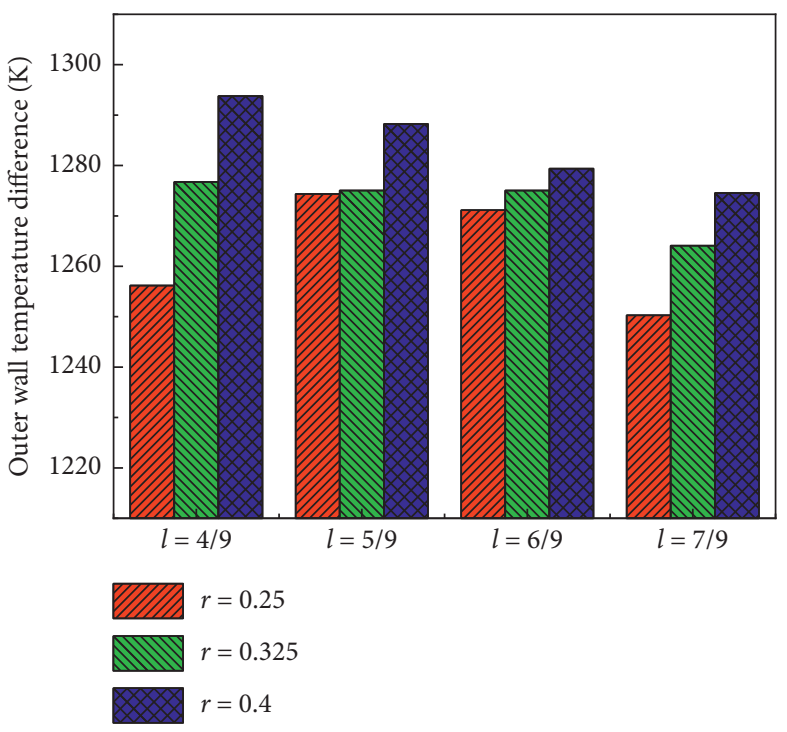

(a)

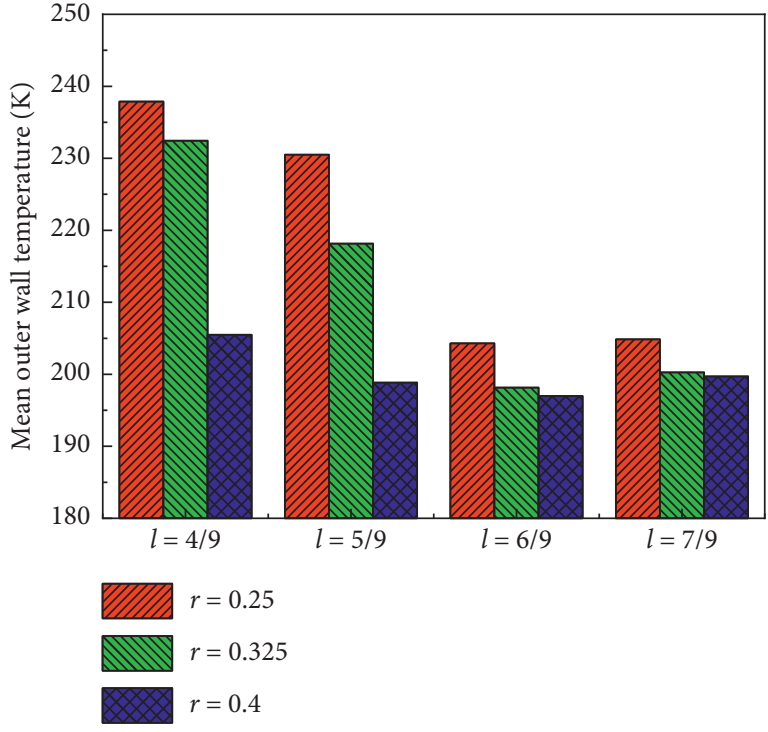

(b)

Figure 10: Mean outer wall temperature and outer wall temperature at different $l$ and $r$.

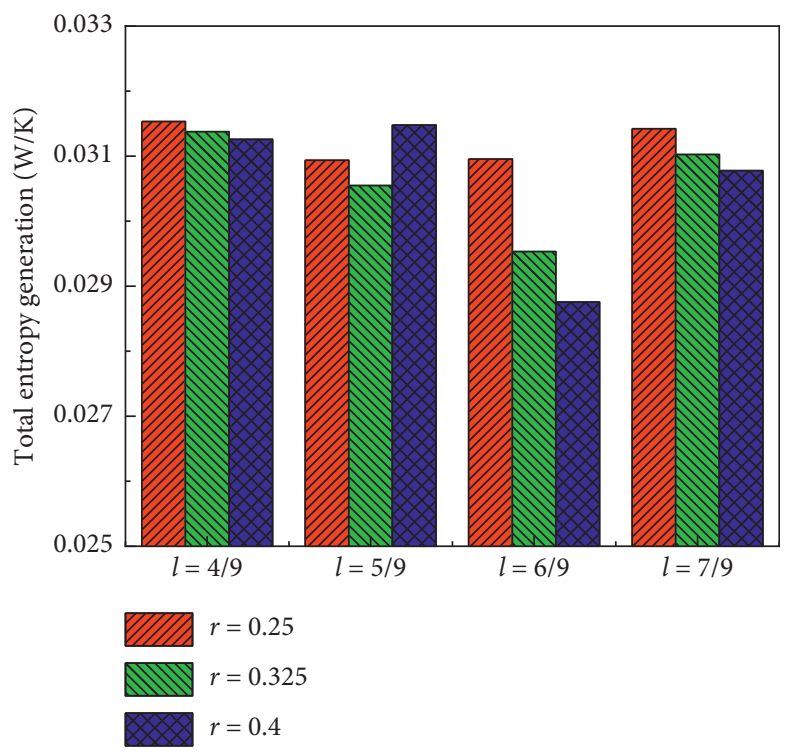

FIgURE 11: Total entropy generation under various $l$ and $r$.

demonstrate the combustion characteristics of the ribbed micro-combustor, it can be analyzed by entropy generation and exergy destruction.

Figure 11 shows the change of total entropy generation at various rib positions $l$ and heights $r$. The different rib positions and heights have an important influence on the entropy field. It is shown that at $l=6 / 9$ and $r=0.4$, the total entropy generation decreases significantly. This is due to the potential to lose more available energy at high gas temperatures. Equation (10) was used to generate the exergy destruction results under various rib positions and heights, as presented in Figure 12. It is easy to see that the exergy destruction decreases drastically at $l=6 / 9$ and $r=0.4$. The results presented in Figures 10 and 13 are both obtained at
$\mathrm{H}_{2}$ and air mass flow rates maintained at $1.347 \times 10^{-7} \mathrm{~kg} / \mathrm{s}$ and $4.632 \times 10^{-6} \mathrm{~kg} / \mathrm{s}$, respectively, and $\mathrm{H}_{2} /$ air equivalent ratio of 1.0. The change trend is the same as the outer wall temperature change trend.

3.3. Effects of Annular Rectangular Rib on Field Synergy Angle. The field synergy principle is an important factor to be considered to further demonstrate and analyze the problem of heat transfer enhancement of micro-combustors. Thus, the field synergy equation of the thermal boundary layer is integrated to prove that reducing the angle between the temperature gradient and the velocity vector is an effective measure to enhance the convective heat transfer. The 


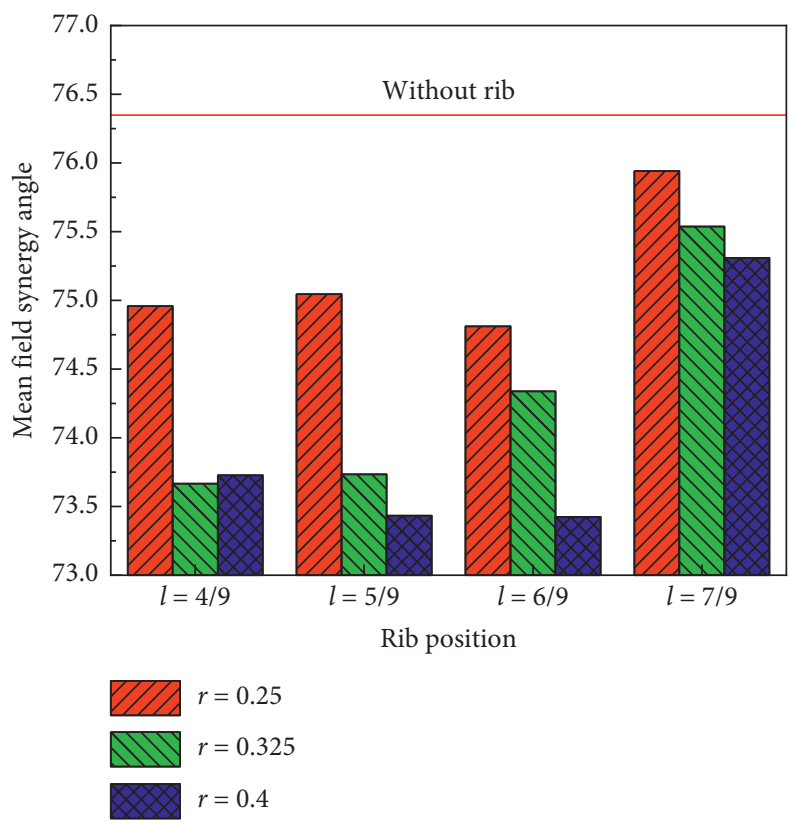

Figure 12: Mean field synergy angle at different rib positions and heights.

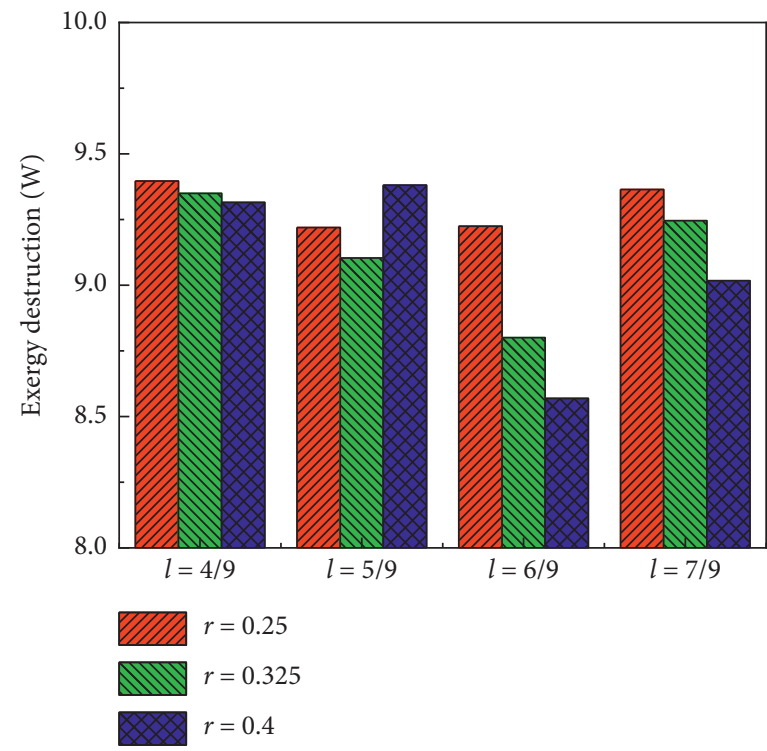

Figure 13: Exergy destruction under various $l$ and $r$.

intensity of heat transfer in the micro-combustor can be more intuitively represented by the field synergy angle.

The nonpremixed micro column combustor was analyzed by the concept of field synergy principle. This principle shows that heat transfer is affected by the characteristics of the temperature field, the velocity field, and also the angle of synergy between the velocity vector and the temperature gradient:

$$
\iiint_{\Omega} \rho C_{p}(\nabla T \cdot \vec{u}) \mathrm{d} V=\iiint_{\Omega}\left(\lambda_{f} \cdot \nabla T\right) \mathrm{d} V .
$$

The dot product of the temperature gradient and the velocity vector can be written as follows:

$$
\vec{u} \cdot \nabla T=|\vec{u}||\nabla T| \cos \theta
$$

Since this study established a 2D axisymmetric model, the synergy angle between the velocity vector and the temperature gradient is expressed as the following equation:

$$
\cos \theta=\frac{(\partial T / \partial x) \cdot u+(\partial T / \partial r) \cdot v}{\sqrt{(\partial T / \partial x)^{2}+(\partial T / \partial r)^{2} \cdot \sqrt{u^{2}+v^{2}}}} .
$$

Figure 14 shows the temperature cloud diagram of different rib positions $l$ and rib heights $r$. After adding the ribs on the micro-combustor, to see the change of the field synergy angle more clearly and intuitively, the cosine value is 


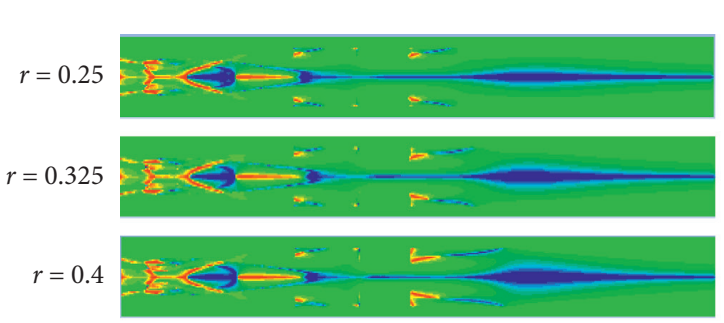

(a) $l=4 / 9$

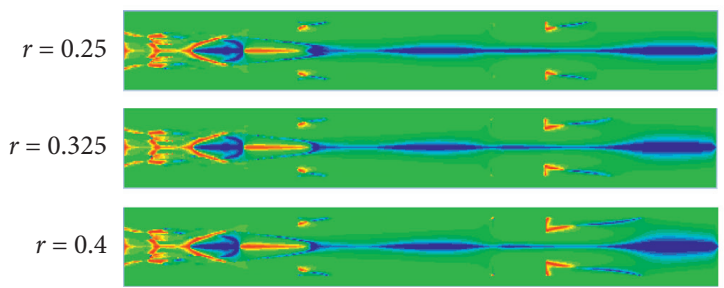

(c) $l=6 / 9$

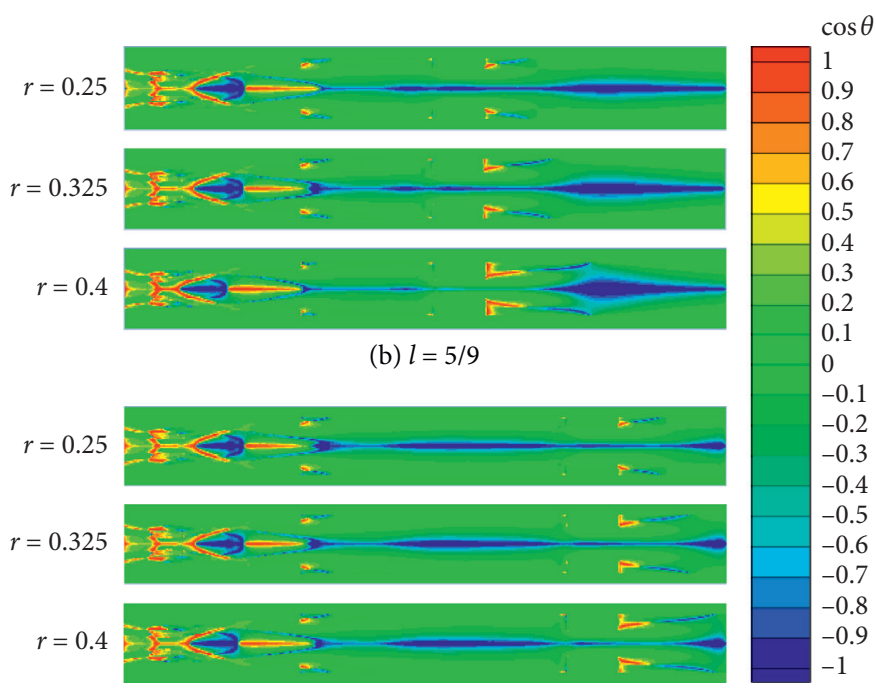

(d) $l=7 / 9$

Figure 14: Cosine of field synergy angle at $l=4 / 9$.

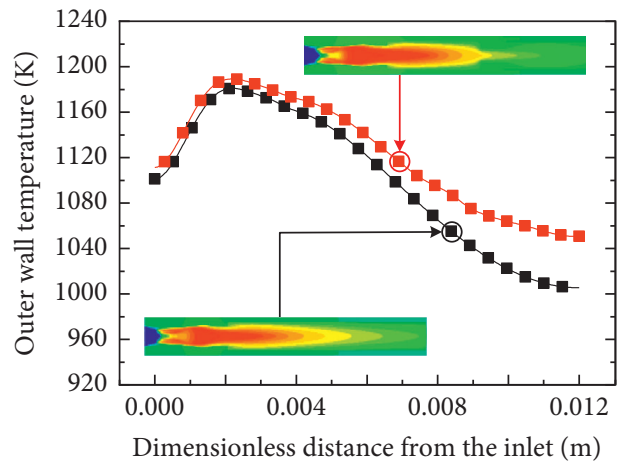

(a)

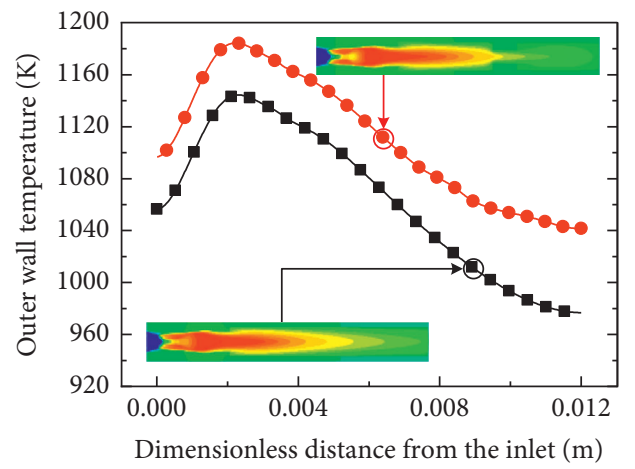

(c)

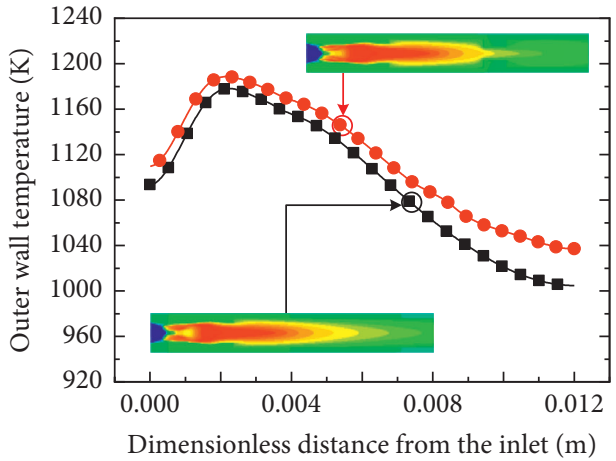

(b)

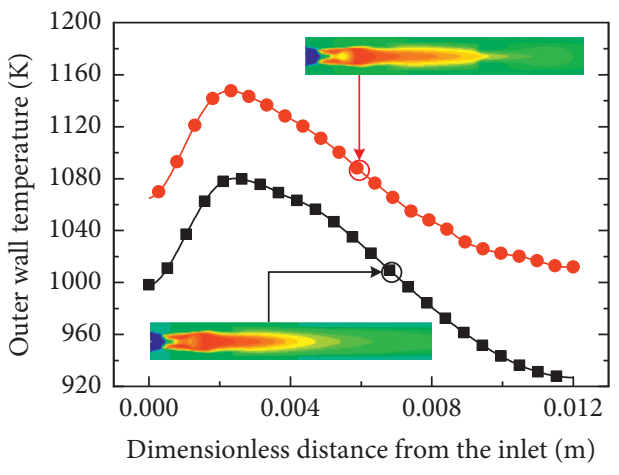

(d)

FIGURE 15: Comparison of outer wall temperature distribution at various equivalent ratios.

converted into an angle and the angle is treated as a range of $0^{\circ}-90^{\circ}$; that is, the angle of $90^{\circ}-180^{\circ}$ takes its complement angle.

A conclusion can be drawn from Figure 12 that the field synergy angle of a nonpremixed micro-combustor having annular rectangular ribs is lower than the field synergy angle of a micro-combustor without ribs. It has been proved again that after the ribs are added, the heat transfer of the microcombustor is enhanced. Similarly, it was established that when the inlet $\mathrm{H}_{2}$ and the air mass flow rates are maintained at $7.438 \times 10^{-8} \mathrm{~kg} / \mathrm{s}$ and $2.573 \times 10^{-6} \mathrm{~kg} / \mathrm{s}$, respectively, at $\mathrm{H}_{2} /$ air equivalent ratio of $1.0, l=6 / 9$, and $r=0.4$, the field synergy angle is minimum, and the best heat transfer performance is obtained. 
TABLE 4: Results of two types of micro-combustors under different equivalence ratios.

\begin{tabular}{|c|c|c|c|c|}
\hline \multirow{2}{*}{ Heat transfer properties } & & \multicolumn{3}{|c|}{ Equivalence ratios } \\
\hline & & 0.9 & 0.8 & 0.7 \\
\hline \multirow{2}{*}{ Mean outer wall temperature $(\mathrm{K})$} & Without rib & 1096.773 & 1064.245 & 1009.532 \\
\hline & With rib & 1116.656 & 1111.187 & 1077.419 \\
\hline \multirow{2}{*}{ Outer wall temperature difference $(\mathrm{K})$} & Without rib & 173.4 & 167.679 & 153.287 \\
\hline & With rib & 151.56 & 142.83 & 135.75 \\
\hline
\end{tabular}

3.4. Effect of Annular Rectangular Ribs on Micro-Combustors at Various $\mathrm{H}_{2}$ /Air Equivalent Ratios. As shown in Figure 15, when $\mathrm{H}_{2}$ mass flow is maintained at $7.438 \times 10^{-8} \mathrm{~kg} / \mathrm{s}$, the micro-combustor with annular rectangular ribs $(l=6 / 9$, $r=0.4$ ) has a higher outer wall temperature at different equivalence ratios $(u=1.0,0.9,0.8$, and 0.7$)$. Moreover, the mean temperature of outer wall and its temperature difference were also compared to better analyze the difference in heat transfer performance between the two combustors at various equivalent ratios. As can be seen from Table 4, the micro-combustor with annular rectangular ribs $(l=6 / 9$, $r=0.4)$ is compared to those without ribs under varying equivalence ratios. Better performance can be obtained by adding annular rectangular ribs to the micro-combustor, and the outer wall temperature of the improved combustor is higher and more uniform at different equivalent ratios.

\section{Conclusions}

The combustion characteristics of nonpremixed $\mathrm{H}_{2}$ /air micro-combustors with and without annular rectangular rib are analyzed by numerical investigation on the temperature distribution, heat transfer uniformity, and field synergy angle in combustion chamber. The combustion characteristics of micro-combustors under various rib positions, rib heights, and equivalent ratios were analyzed. Some specific conclusions can be summarized as follows:

(1) The use of annular rectangular ribs can create a turbulent zone in the micro-combustor, which enhances the heat transfer efficiency between the inner wall of the combustion chamber and the burned fuel.

(2) As the annular rectangular ribs approach the flame center, the positive effect of turbulent zone will be weakened, and the temperature will not increase with the increase of fin height. Also, as the rib height increases, the turbulence zone becomes wider and increases; consequently, the heat transfer performance is enhanced.

(3) When the $\mathrm{H}_{2}$ mass flow rate is $7.438 \times 10^{-8} \mathrm{~kg} / \mathrm{s}$ and the air mass flow rate is $2.576 \times 10^{-6} \mathrm{~kg} / \mathrm{s}$, the most uniform heat transfer and a minimum field synergy angle are obtained at $l=6 / 9$ and $r=0.4$. Meanwhile, the entropy generation and exergy destruction are significantly decreased. However, the optimum $l$ and $r$ greatly depend on the inlet mass flow of $\mathrm{H}_{2} /$ air mixture.

(4) Based on the comparisons between both combustors performance under various equivalence ratios, it was established that the micro-combustor with annular rectangular ribs contributes significantly to a higher and more uniform outer wall temperature.

\section{Nomenclature}

$u, v: \quad$ Velocity component in the $x, r$-direction, $\mathrm{m} / \mathrm{s}$

$\rho: \quad$ Gas density, $\mathrm{kg} / \mathrm{m}^{3}$

$P: \quad$ Fluid pressure, $\mathrm{Pa}$

$\tau_{i j}: \quad$ Stress tensor, $\mathrm{N}$

$u_{j}$ : $\quad$ Velocity component in the $x_{j}$ direction, $\mathrm{m} / \mathrm{s}$

$(j=1,2,3)$

$H: \quad \quad$ Enthalpy of the gas, J/kg

$F_{i, j}: \quad$ Energy flux in the $x_{i}$ direction, $\mathrm{W}$

$m_{l}: \quad$ Mass fraction of species, $\mathrm{J} / \mathrm{kg}$

$J_{l, j}$ : $\quad$ Diffusion flux of species $l$ in the $x_{j}$ direction, $\mathrm{kmol} /\left(\mathrm{m}^{2} \cdot \mathrm{s}\right)$

$R_{l}: \quad$ Chemical reaction product rate, $\mathrm{kmol} /\left(\mathrm{m}^{3} \cdot \mathrm{s}\right)$

$\lambda_{w}: \quad$ Wall thermal conductivity, $\mathrm{W} / \mathrm{m} \cdot \mathrm{K}$

$R: \quad$ Universal gas constant, $\mathrm{J} / \mathrm{Kmol} \cdot \mathrm{K}$

$M_{l}$ : $\quad$ Molar mass of species

$T_{\text {outwall,max }}$ : Maximum outer wall temperature, $\mathrm{K}$

$T_{\text {outwall,min }}$ : Minimum outer wall temperature, $\mathrm{K}$

$S: \quad$ Specific entropy

$U: \quad$ Specific internal energy

$u_{j}: \quad$ Chemical potential of species $j$

$n_{j}$ : $\quad$ Number density of species $j$

$S_{\text {gen }}: \quad$ Total entropy generation

M: $\quad$ Flow rate of gas

$E_{\text {des: }} \quad$ Exergy destruction

$T_{0}: \quad$ Ambient temperature, $298 \mathrm{~K}$

$C_{p}: \quad$ Specific heat capacity

$\vec{u}: \quad$ Speed vector

$\nabla T: \quad$ Temperature gradient

$\Theta: \quad$ Synergy angle

$\mathrm{d} T / \mathrm{d} x: \quad$ Axial temperature gradient

$\mathrm{d} T / \mathrm{d} r: \quad$ Radial temperature gradient.

\section{Data Availability}

The data used to support the findings of this study are included within the article.

\section{Conflicts of Interest}

The authors declare that they have no conflicts of interest.

\section{Acknowledgments}

This work was supported by the National Natural Science Foundation of China (Grant nos. 51806250 and 61903287). 
The authors are also thankful for the support by the Natural Science Foundation of Hunan Province, China (Grant no. 2019JJ50836).

\section{References}

[1] S. K. Chou, W. M. Yang, J. Li, and Z. W. Li, "Porous media combustion for micro thermophotovoltaic system applications," Applied Energy, vol. 87, no. 9, pp. 2862-2867, 2010.

[2] J. F. Pan, D. Wu, Y. X. Liu, H. F. Zhang, A. K. Tang, and H. Xue, "Hydrogen/oxygen premixed combustion characteristics in micro porous media combustor," Energy Procedia, vol. 61, pp. 1279-1285, 2014.

[3] J. Li, H. Cui, and Y. Tian, "Nonlinearity analysis of measurement model for vision-based optical navigation system," Acta Astronautica, vol. 107, pp. 70-78, 2015.

[4] J. Li, Q. Li, Y. Wang, Z. Guo, and X. Liu, "Fundamental flame characteristics of premixed $\mathrm{H}_{2}$-air combustion in a planar porous micro-combustor," Chemical Engineering Journal, vol. 283, pp. 1187-1196, 2016.

[5] J. Li, Y. Wang, J. Chen, J. Shi, and X. Liu, "Experimental study on standing wave regimes of premixed $\mathrm{H}_{2}$-air combustion in planar micro-combustors partially filled with porous medium," Fuel, vol. 167, pp. 98-105, 2016.

[6] C.-H. Leu, S.-C. King, J.-M. Huang et al., "Visible images of the catalytic combustion of methanol in a micro-channel reactor," Chemical Engineering Journal, vol. 226, pp. 201-208, 2013.

[7] Y.-H. Li, G.-B. Chen, T.-S. Cheng, Y.-L. Yeh, and Y.-C. Chao, "Combustion characteristics of a small-scale combustor with a percolated platinum emitter tube for thermophotovoltaics," Energy, vol. 61, no. 4, pp. 150-157, 2013.

[8] J. Ran, L. Li, X. Du, R. Wang, W. Pan, and W. Tang, "Numerical investigations on characteristics of methane catalytic combustion in micro-channels with a concave or convex wall cavity," Energy Conversion and Management, vol. 97, pp. 188-195, 2015.

[9] S. A. Smyth and D. C. Kyritsis, "Experimental determination of the structure of catalytic micro-combustion flows over small-scale flat plates for methane and propane fuel," Combustion and Flame, vol. 159, no. 2, pp. 802-816, 2012.

[10] T. A. Wierzbicki, I. C. Lee, and A. K. Gupta, "Combustion of propane with $\mathrm{Pt}$ and $\mathrm{Rh}$ catalysts in a meso-scale heat recirculating combustor," Applied Energy, vol. 130, no. 130, pp. 350-356, 2014.

[11] T. A. Wierzbicki, I. C. Lee, and A. K. Gupta, "Rh assisted catalytic oxidation of jet fuel surrogates in a meso-scale combustor,” Applied Energy, vol. 145, pp. 1-7, 2015.

[12] V. Vijayan and A. K. Gupta, "Combustion and heat transfer at meso-scale with thermal recuperation," Applied Energy, vol. 87, no. 8, pp. 2628-2639, 2010.

[13] V. Vijayan and A. K. Gupta, "Flame dynamics of a meso-scale heat recirculating combustor," Applied Energy, vol. 87, no. 12, pp. 3718-3728, 2010.

[14] V. Shirsat and A. K. Gupta, "Performance characteristics of methanol and kerosene fuelled meso-scale heat-recirculating combustors," Applied Energy, vol. 88, no. 12, pp. 5069-5082, 2011.

[15] T. A. Wierzbicki, I. C. Lee, and A. K. Gupta, "Performance of synthetic jet fuels in a meso-scale heat recirculating combustor," Applied Energy, vol. 118, no. 1, pp. 41-47, 2014.

[16] G. Bagheri and S. E. Hosseini, "Impacts of inner/outer reactor heat recirculation on the characteristic of micro-scale combustion system," Energy Conversion and Management, vol. 105, pp. 45-53, 2015.

[17] S. E. Hosseini and M. A. Wahid, "Investigation of bluff-body micro-flameless combustion," Energy Conversion and Management, vol. 88, pp. 120-128, 2014.

[18] J. Wan, A. Fan, H. Yao, and W. Liu, "Flame-anchoring mechanisms of a micro cavity-combustor for premixed $\mathrm{H}_{2}$ /air flame," Chemical Engineering Journal, vol. 275, pp. 17-26, 2015.

[19] J. Wan, W. Yang, A. Fan et al., "A numerical investigation on combustion characteristics of $\mathrm{H}_{2}$ /air mixture in a microcombustor with wall cavities," International Journal of Hydrogen Energy, vol. 39, no. 15, pp. 8138-8146, 2014.

[20] G. Wu, Z. Lu, W. Pan, Y. Guan, and C. Z. Ji, "Numerical and experimental demonstration of actively passive mitigating self-sustained thermoacoustic oscillations," Applied Energy, vol. 222, pp. 257-266, 2018.

[21] G. Wu, Z. Lu, X. Xu et al., "Numerical investigation of aeroacoustics damping performance of a Helmholtz resonator: effects of geometry, grazing and bias flow," Aerospace Science and Technology, vol. 86, pp. 191-203, 2019.

[22] S. Y. Jejurkar and D. P. Mishra, "Effects of wall thermal conductivity on entropy generation and exergy losses in a $\mathrm{H}_{2}$ air premixed flame microcombustor," International Journal of Hydrogen Energy, vol. 36, no. 24, pp. 15851-15859, 2011.

[23] A. Briones, A. Mukhopadhyay, and S. Aggarwal, "Analysis of entropy generation in hydrogen-enriched methane-air propagating triple flames," International Journal of Hydrogen Energy, vol. 34, no. 2, pp. 1074-1083, 2009.

[24] G. Wu, D. Wu, Y. Li, and Li Meng, "Effect of acetone-nbutanol-ethanol $(\mathrm{ABE})$ as an oxygenate on combustion, performance, and emission characteristics of a spark ignition engine," Journal of Chemistry, vol. 2020, Article ID 7468651, 11 pages, 2020.

[25] Y. Li, W. Tang, Y. Chen, J. Liu, and C.-f. F. Lee, "Potential of acetone-butanol-ethanol (ABE) as a biofuel," Fuel, vol. 242, pp. 673-686, 2019.

[26] K. Wei, Y. Yang, H. Zuo, and D. Zhong, "A review on ice detection technology and ice elimination technology for wind turbine," Wind Energy, 2019.

[27] X. Zhao, J. E, Z. Zhang et al., "A review on heat enhancement in thermal energy conversion and management using field synergy principle," Applied Energy, vol. 257, Article ID 113995, 2020.

[28] S. Akhtar, J. C. Kurnia, and T. Shamim, "A three-dimensional computational model of $\mathrm{H}_{2}$-air premixed combustion in noncircular micro-channels for a thermo-photovoltaic (TPV) application," Applied Energy, vol. 152, no. 1, pp. 47-57, 2015.

[29] W. M. Yang, S. K. Chou, K. J. Chua, J. Li, and X. Zhao, "Research on modular micro combustor-radiator with and without porous media," Chemical Engineering Journal, vol. 168, no. 2, pp. 799-802, 2011.

[30] W. M. Yang, K. J. Chua, J. F. Pan, D. Y. Jiang, and H. An, "Development of micro-thermophotovoltaic power generator with heat recuperation," Energy Conversion and Management, vol. 78, no. 78, pp. 81-87, 2014.

[31] W. Yang, D. Jiang, C. K. Y. Kenny, Z. Dan, and J. Pan, "Combustion process and entropy generation in a novel microcombustor with a block insert," Chemical Engineering Journal, vol. 274, no. 3, pp. 231-237, 2015.

[32] D. Jiang, W. Yang, K. J. Chua, and J. Ouyang, "Thermal performance of micro-combustors with baffles for thermophotovoltaic system," Applied Thermal Engineering, vol. 61, no. 2, pp. 670-677, 2013. 
[33] D. Jiang, W. Yang, and A. Tang, "Development of a hightemperature and high-uniformity micro planar combustor for thermophotovoltaics application," Energy Conversion and Management, vol. 103, pp. 359-365, 2015.

[34] A. Tang, J. Pan, W. Yang, Y. Xu, and Z. Hou, "Numerical study of premixed hydrogen/air combustion in a micro planar combustor with parallel separating plates," International Journal of Hydrogen Energy, vol. 40, no. 5, pp. 2396-2403, 2015.

[35] Y. Su, Q. Cheng, J. Song, and M. Si, "Numerical study on a multiple-channel micro combustor for a micro-thermophotovoltaic system," Energy Conversion \& Management, vol. 120, pp. 197-205, 2016.

[36] S. Chen, "Analysis of entropy generation in counter-flow premixed hydrogen-air combustion," International Journal of Hydrogen Energy, vol. 35, no. 3, pp. 1401-1411, 2010.

[37] S. Chen, H. Han, Z. Liu, J. Li, and C. Zheng, "Analysis of entropy generation in non-premixed hydrogen versus heated air counter-flow combustion," International Journal of $\mathrm{Hy}$ drogen Energy, vol. 35, no. 10, pp. 4736-4746, 2010.

[38] S. Chen, Z. Liu, J. Liu, J. Li, L. Wang, and C. Zheng, "Analysis of entropy generation in hydrogen-enriched ultra-lean counter-flow methane-air non-premixed combustion," International Journal of Hydrogen Energy, vol. 35, no. 22, pp. 12491-12501, 2010.

[39] A. Emadi and M. D. Emami, "Analysis of entropy generation in a hydrogen-enriched turbulent non-premixed flame," International Journal of Hydrogen Energy, vol. 38, no. 14, pp. 5961-5973, 2013.

[40] A. Datta, "Effects of gravity on structure and entropy generation of confined laminar diffusion flames," International Journal of Thermal Sciences, vol. 44, no. 5, pp. 429-440, 2005.

[41] H. Ban, S. Venkatesh, and K. Saito, "Convection-diffusion controlled laminar micro flames," Journal of Heat Transfer, vol. 116, no. 4, pp. 954-959, 1994.

[42] P. R. Resende, M. Ayoobi, and A. M. Afonso, "Numerical investigations of micro-scale diffusion combustion: a brief review," Applied Sciences, vol. 9, no. 16, p. 3356, 2019.

[43] J. E, X. Zhao, W. Zuo, Z. Zhang, and M. Pham, "Numerical investigation on the combustion characteristics of non-premixed hydrogen-air in a novel micro-combustor," Applied Thermal Engineering, vol. 110, pp. 665-677, 2017.

[44] J. E, M. Zhao, Q. Zuo, B. Zhang, Z. Zhang, Q. Peng et al., "Effects analysis on diesel soot continuous regeneration performance of a rotary microwave-assisted regeneration diesel particulate filter," Fuel, vol. 260, pp. 116-353, 2019.

[45] J. E, X. Zhao, G. Liu, B. Zhang, Q. Zuo, K. Wei et al., "Effects analysis on optimal microwave energy consumption in the heating process of composite regeneration for the diesel particulate filter," Applied Energy, vol. 254, pp. 113-736, 2019.

[46] C. H. Kuo and P. D. Ronney, "Numerical modeling of nonadiabatic heat-recirculating combustors," Proceedings of the Combustion Institute, vol. 31, no. 2, pp. 3277-3284, 2007. 